\title{
Erratum to: Sacral Neuromodulation: Does It Affect the Rectoanal Angle in Patients with Fecal Incontinence?
}

\author{
Ö. Uludağ $\cdot$ S. M. P. Koch · R. F. Vliegen • \\ C. H. C. Dejong • W. G. van Gemert • \\ C. G. M. I. Baeten
}

Published online: 17 March 2010

(c) Société Internationale de Chirurgie 2010

\section{Erratum to: World J Surg \\ DOI 10.1007/s00268-010-0474-8}

A revised Conclusions section is as follows:

Although the neural supply of the pelvic floor musculature is different from that of the external anal sphincter, this study did not show a statistically significant change in rectoanal angle during SNM. However, a clear tendency was observed toward a decreased or sharpened rectoanal angle during rest, squeeze, and Valsalva's maneuver and an increased or blunted rectoanal angle during defecation. A small population size may account for these findings. Further research is necessary for a better understanding of the mechanism of action of SNM.

The online version of the original article can be found under doi:10.1007/s00268-010-0474-8.

Ö. Uludağ $(\bowtie) \cdot$ S. M. P. Koch · C. H. C. Dejong ·

W. G. van Gemert - C. G. M. I. Baeten

Department of Surgery, Maastricht University Medical Centre, P.O. Box 5800, 6202 AZ Maastricht, The Netherlands

e-mail: ouludag@hotmail.com

R. F. Vliegen

Department of Radiology, Maastricht University Medical

Centre, P.O. Box 5800, 6202 AZ Maastricht, The Netherlands

C. H. C. Dejong

Maastricht University Medical Centre, Nutrim, P.O. Box 5800,

6202 AZ Maastricht, The Netherlands 